\title{
Lasar Segall e as festas da SPAM*
}

Fernando Antonio Pinheiro Filho

Entre as atividades desenvolvidas por Lasar Segall, pintor lituano que migra para o Brasil em 1923, após dez anos de formação expressionista na Alemanha, este trabalho toma por objeto os bailes de carnaval da Sociedade Pró-Arte M oderna (SPAM ), fundada por ele em 1932, à frente de um grupo de artistas, de mecenas e dos setores da elite a que se ligou ${ }^{1}$. A SPAM funcionou por dois anos como centro aglutinador de uma socia bilidade que girava em torno da arte como elemento de distinção social. $N$ essa ocasião, atuando como produtor cultural, demonstra a mesma habilidade de representação da interioridade - não mais da alma, que visara em sua produção de cavalete, seguindo de perto a estética expressionista conforme $K$ andinsky a desenvolvera, mas do grupo social e da cidade que o abriga -, instituindo ao mesmo tempo os marcadores simbólicos de identidade do grupo que acompanharemos.

Como primeiro ato desse movimento, Segall idealiza uma festa para o reveillon de 1933, em comemoração da fundação da SPAM, na casa da bailarina C hinita U IIman. N ão há dados suficientes para incorporar 0 evento à análise, mas seu tema - "São Silvestre em farrapos" - justifica no mínimo a menção, porque antecipa o cuidado com a vestimenta que será um dos aspectos controlados por Segall nos bailes de carnaval. A qui, 0 protocolo social temporariamente invertido exige da porção spamista da elite paulistana que compareça a uma festa de Ano N ovo simulando po-
*Este artigo é versão ligeiramente modificada de um capítulo do livro a ser publicado pela Editora C osac \& N aify.

1. Em São Paulo, Lasar Segall liga-se ao modernismo por intermédio de $M$ ário de A ndrade e passa a freqüentar os salõesaris tocráticos, integrandose auma fração da elite que vê nele uma referência de renovação estética. 
sicionamento social antípoda ao que ocupa, marcado na roupa falsamente maltrapilha. Desse modo, a transposição plástica da estratificação social pode servir de metáfora do marco zero da entidade, bem como celebração da unidade interna do grupo. Com maior apoio no material empírico, a análise dos bailes procura reconstituir as marcações simbólicas a partir das quais o grupo, com base nas soluções cenográficas de Segall, se representa enquanto constrói no imaginário social a visibilidade de si, da cidade e da sociedade a que pertence.

\section{Na cidade de SPAM}

Ainda antes do período brasileiro, Segall participara dos bailes de carnaval daA cademia de $D$ resden organizados pel os alunos, os quais, respeitadas as diferenças culturais, trazem a marca da suspensão temporária da ordem social em benefício da instituição onírica de outra realidade, que se materializa na tarefa artística da construção de símbolos adequados ao tema escolhido, padrão que se repetirána SPA M . A ssociadosà necessidade de arrecadação de fundos para a entidade, e, sobretudo, ao gosto pela celebração festiva da sociabilidade interna ao grupo e à oportunidade de produção artística assim ensejada, esses traços biográficos confluem na dedicação extrema e totalizante com que Segall tomará a pulso a concepção e a realização das duas festas de carnaval da SPAM . Embora realizadas por meio da divisão do trabalho, com a colaboração ativa em suas especialida des dos diversos artistas da SPAM , é Segall que centraliza a organização geral e quem mais se identifica com as realizações, sendo imediatamente reconhecido como seu principal protagonista.

D e fato, a empresa segaliana estende-se da concepção e preparação do espaço cênico em que o evento se realiza à confecção de fantasias, passando pela invenção do tema, a decoração do salão com uso de variadastécnicas e o desenvolvimento das coreografias e rituaislúdicos que compõem 0 andamento da festa. $\mathrm{N}$ a dimensão imaginária, 0 sentido das festas é pensa do como estando presente em todas as partes, embora não de forma específica em nenhuma delas. $R$ azão pela qual é preciso reconstituí-las separa damente, atentando, num primeiro momento, para a montagem do simbolismo manifesto em cada uma para, em seguida, buscar a recomposição de seu significado mais amplo.

A primeira festa ocorreu em 16 de fevereiro de 1933, com o tema "C arnaval na cidade de SPAM ". 0 projeto de Segall concebia um simu- 
lacro de cidade cujo ambiente feérico aproximava a de um mundo à parte, em que as instituições e os agentes sociais estão representados com sinais invertidos ou deslocados de seu eixo semântico usual, permitindo à hierarquia social ser atravessada por uma mistura de tipos. 0 efeito de estranhamento imediato seria arrefecido ao longo do evento, à medida que os novos marcadores da ordem fossem tornando- se familiares. $N$ esse sentido, a festa era pautada por uma série de acontecimentos ritualizados, em que cada novidade encaixava-se na construção simbólica realizada pelos artistas e a reforçava. A idéia de um projeto com grande coerência ideológica implica assim atenção a cada um dos detalhes para garantir a harmonia do todo.

0 convite graficamente bem elaborado acompanhava-se de um programa; no conjunto, os documentos procuravam detalhar de maneira didática aos convivas o sentido da celebração, introduzindo-os previamente no universo criado. Assim, a folha de rosto do convite, abaixo de um desenho de Segall, traz os seguintes dizeres:

As altas autoridades da cidade de SPAM convidamV. S. para a recepção do Príncipe $C$ arnaval, a realizar-se na praça pública da cidade de SPAM , no dia 16 de fevereiro às 23 horas².

A lerta portanto para o ápice da festa, e nesse passo revela já sua concepção cênica, quase sinfônica, como um detalhe a ser retido. N o verso da folha, informa-se:

O s convidados representarão a massa popular. Todas as fantasias: gente do povo, fantasiados, mascates, apaches, saltimbancos, mendigos, effarrapados, midinettes, grilos, militares, plutocratas, marinheiros, crianças, altas autoridades, caipiras, vagabundos, turistas, ciganos, engraxates, bombeiros, novos ricos etc.

Instaura-se aqui uma separação entre os spamistas e seus convidados: aos primeiros estão reservados os papéis ativos na encenação que serve de mote à festa, enquanto aos outros sobra o papel de "massa popular". 0 recorte não é econômico ou político, já que a esta última categoria pertencem também os plutocratas, as altas autoridades, os novos ricos. A lém disso, a disparidade semântica da classificação, que sugere simetria lógica entre, por exemplo, categorias como fantasiados, mendigos e militares, dissimula um pouco a divisão, já que vários spamistas atuarão no interior
2. Este documento e todososoutros aqui citados se encontram no A rquivo Lasar Segall, M useu Lasar Segall, IPHAN . 
de algumas delas, com a ritualização de sua performance sendo aquilo que os separa da massa popular.

Completam o convite a informação sobre "o cerimonial soleníssimo da recepção do Príncipe C arnaval e do seu imponente séquito" e os créditos a Segall, pela ornamentação dos salões e a direção dos festejos, e a seus colaboradores, discriminados um a um. No mais, importa atentar para o poema, que preenche a última página, de $\mathrm{M}$ ário de Andrade, autor que desde a chegada de Segall o recebe como parceiro na renovação artística que empreendia, aproximando os projetos estéticos de modernistas e expressionistas.

O elefante, o grilo, a cunhã,

Policiadamente insensatos,

Espicham, pincham feito gatos,

Pra ver, na cidade de Spam,

Dão M omo, príncipe galã

Com seu séquito sem respeito,

$\mathrm{R}$ eceber honras do Prefeito

D a heróica cidade de Spam.

E se abre a farra fanfarrã!

D outores, mendigos, exóticas

Pernas, carruagens estrambóticas

Barcarolas e rataplã,

H eróis nascidos na antevéspera,

Jogadores de box e víspora,

Esporas, cascas, besta ruã...

É a fauna urbana e suburbana

$D$ ançando o fox, a queromana

Corda bamba, valsa alemã

Samba, tango, jongo e bolero!

Vende ver isso ao Trocadero

$\mathrm{N}$ a carnavalada de Spam!

Com seu ritmo sincopado e adequada leveza, cuja graça é reforçada pelo uso calculado de rimas pobres, o poemeto dá nova expressão às preocupações didáticas reiteradas no convite. Alude à mistura de tipos 
que numa festa de carnaval é pautada pela quebra das hierarquias tradicionais e alerta que a confusão programada se desencadeia a partir de um momento solene que abre a encenação. 0 s muitos ritmos musicais cita dos, cujo efeito poético redobra o andamento da peça e instila sinestesica mente o desejo hedonista, dar-se-ão em função da recepção do Príncipe C arnaval - agora identificado à figura de M omo - , cuja aparição dá sentido à presença da "fauna urbana e suburbana". R eiteram-se os sinais, portanto, de que os convidados do grupo spamista devem esperar uma festa algo distante da tradição brasileira de carnaval, diferença presente tanto na cenografia e no desenvolvimento narrativo como no papel desempenhado por cada um, conforme pertença ou não ao grupo. Essa mesma preocupação repete-se no programa da festa, previamente distribuído junto com o convite.

De acordo com ele, a encenação divide-se em dez movimentos, da entrada do Príncipe $C$ arnaval ao baile popular, conforme o projeto de Segall e seus colaboradores, John Graz, Esther Bessel e Jenny Segall, nos figurinos; C hinita U IIman, na coreografia; e C amargo Guarnieri ${ }^{3}$, na direção musical. A descrição dos movimentos faz-se nos seguintes termos:

$1^{2}$ - Entrada e D esfile do Cortejo

M úsica de $\mathrm{C}$ amargo Guarnieri

Personagens: o jovial bobo da corte, a deslumbrante madrinha, o romântico trovador, os graciosos pagens, Sua M ajestosa A Iteza O Príncipe, seu fogoso corcel, 0 sagaz ministério, o poderoso exército, o temível carrasco, as aristocráticas damas da corte.

$2^{2}$ - Inauguração da estátua de Spaminondas

Esta magnífica obra de arte, de renome mundial, acaba de ser adquirida telegraficamente pelo British M useum.

$3^{2}$ - Hino de Spam

M úsica de C amargo Guarnieri

Personagens: o dirigente do coro, o corpo coral masculino, os grilos, as donzelas spamistas.

$4^{2}$ - O ferta ao Príncipe pelo povo spamista da rainha da beleza, M iss Spam

Personagens: 0 solene prefeito, a formosa M iss Spam, o autêntico e suntuoso baldaquim Luiz X V.

$5^{9}$ - C oroação da nova rainha e homenagem da corte ao casal principesco.

60 - A clássica canção do trovador.

70 - Bailado das virgens pelas donzelas spamistas.
3. John Graz, pintor suíço de formação expres sionista, radicou-se no Brasil em 1920, expondo na Semana de 1922 e realizando afrescosnas mansões da elite que freqüentava. Jenny, es posa de Segall, eraherdeira da família Klabin, proprietária da indústria de papel.A bailarina porto-alegrense C hinitaU IIman fora membro do corpo de baile daEscolade Dança de M ary W igman, em $D$ resden, nos anos de1920. Camargo Guarnieri firma-se nos anos de 1930 como o principal criador brasileiro na área do canto de câmara. 
$8^{\mathfrak{Q}}$ - H ino Spamtriótico cantado pelo povo spamista.

92 - D ança grotesca

Personagens: o Príncipe, a corte, as delegações populares.

$10^{2}$ - Baile popular

D urante o resto da noite o Príncipe Carnaval e os nobres membros de sua corte circularão democraticamente entre os spamistas.

Às 2 horas da madrugada será posto em circulação o importante matutino "A Vida de Spam".

Segue ainda a nomeação de todo o elenco responsável pela pantomima, com destaque para os papéis principais: $K$ itty Bodenheim como bobo da corte; Samuel K labin, patriarca da família e avô de Jenny, como Príncipe $C$ arnaval; A ndrada C oelho como o carrasco; A lice R ossi, artista plástica e esposa de Paulo R ossi O sir, como M iss SPAM ; Lima N etto como trovador; C lovis $\mathrm{M}$ artins de $\mathrm{C}$ amargo, casado com uma das filhas de $\mathrm{O}$ lívia Guedes Penteado, importante mecenas e animadora de concorrido salão em sua mansão, decorada por Segall em 1924, como porta-bandeira; PauIo $\mathrm{M}$ endes de Almeida, procurador do Estado e crítico de arte, como prefeito; C amargo Guarnieri como dirigente do coro; e C hinita U IIman como bailarina principal. $\mathrm{N}$ o total, entre componentes da marinha, pagens, ministério, exército, corpo coral, donzelas, damas da corte e pelotão de grilos, são citados os nomes de 86 membros do grupo spamista.

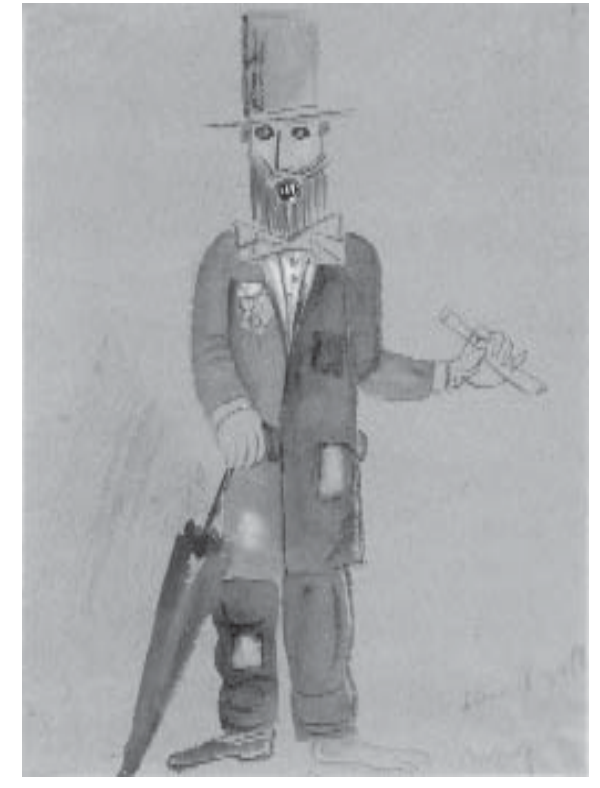

Lasar Segall, 0 prefeito. Carnaval da SPAM, 1933 [Projeto para figurino]. Aquarela. Museu Lasar Segall (fotógrafo Luiz Hossaka). 
H á dois aspectos que merecem atenção nessa reconstituição das preliminares da festa pelo modo especial de recrutamento de seus convivas, recurso metodológico que as circunstâncias de distância temporal tornam imprescindível. D e um lado, o andamento do programa põe em cena uma série de representações que mimetizam símbolos da nacionalidade: a SPAM dispõe de um hino, de um herói nacional (Spaminondas), de autoridades públicas. Se cada um deles tem sua manipulação cercada de um protocolo inusitado, mensurável apenas na escala da imaginação criadora de Segall e seus assessores, que Ihes confere tintas de uma calculada anarquia festiva, nenhum representa direta ou indiretamente os símbolos de nacionalidade brasileira ou remete a estereótipos estabelecidos de uma cultura brasileira.Veremosem que termosa cidade de SPAM pode ser vista como um simulacro de São Paulo, mas, se isso é verdadeiro, não há por outro lado nenhuma intenção de expressão da "brasilidade". N ote-se que isso se dá no momento imediatamente anterior ao início de uma verda deira cruzada que $M$ ário de Andrade empreenderá em busca justamente dessa expressão mais autêntica, e que o levará ao longo dos anos de 1930 a afastar-se de Segall, trocando-o por Portinari como referência maior nas artes plásticas. E M ário é ativo participante do baile, não só por sua presença como pelo poema mencionado e pela produção do jornal "A Vida de SPAM ", que divide com Alcantara M achado e o crítico literário Sérgio M illiet, figura de ponta do modernismo que retornara ao Brasil em 1925, após uma temporada na Europa.

$\mathrm{N}$ a outra ponta, 0 registro individual do elenco spamista em seus respectivos papéis reforça a marcação da diferença já discutida, agora transposta na divisão categórica entre os que têm direito a nome próprio - e cuja simples presença se enuncia como atração da festa, em virtude da posse de um talento especial a serviço dela ou da posse mesma do nome como garantia prévia de pertencimento à "nossa melhor sociedade" 4 - e os anônimos componentes da "massa popular", qualquer que seja a posição que de fato ocupem no espaço social e cuja função na encenação é a de figurante.

Q uanto à cenografia e à decoração, já se viu que se trata de montar uma cidade em miniatura. A cidade de SPAM dispõe de monumento, circo, presídio, jardim zoológico, restaurantes e bares, praça pública. N ão Ihe faltam instituições de vários tipos acomodadas nesse espaço urbano, sejam políticas (prefeitura), jurídicas (cadeia), econômicas (a SPAM possui moeda própria, o spamote, que devia ser adquirido na entrada, na cotação de
4. A expressão aparece em carta de Guilherme de Almeida a Segall, de 9 de fevereiro de 1931 (Arquivo Lasar Segall, M useu Lasar Segall, IPHAN ), em que 0 poeta alude ao projeto comum defundar um centro de arte moderna que reúna "nossamelhor sociedade", expressão reveladora do sentido social da entidade. 
um para mil réis) ou concernentes à presença da sociedade civil (imprensa). Todo o espaço está decorado com painéis pintados coletivamente a partir da concepção de Segall. Comparado com a fatura empregada por Segall em outras empresas do gênero - como as decorações do Baile Futurista do A utomóvel Club, em 1924, e do pavilhão modernista na residência de 0 lívia Guedes Penteado, ocasiões em que lança mão de recursos caros às vanguardas européias, como a geometrização de formas abstratas, em que parece querer afirmar a diferença de que era portador - , há uma atenuação da geometrização visando a lograr o efeito de figuração de uma cidade; a gama de tonal idades empregadas apresenta variações em que predomina o ocre. 0 sdesenhos de formas simplificadas e corte expressionista têm grande força expressiva graças sobretudo aos dados irreverentes que incorporam: o porta-bandeira usa uma caçarola invertida como chapéu, escovões servem de ombrei ras aos so ldados, na vestimenta das autoridades há uma textura e um cai mento que lhes empresta ares de mendigo.

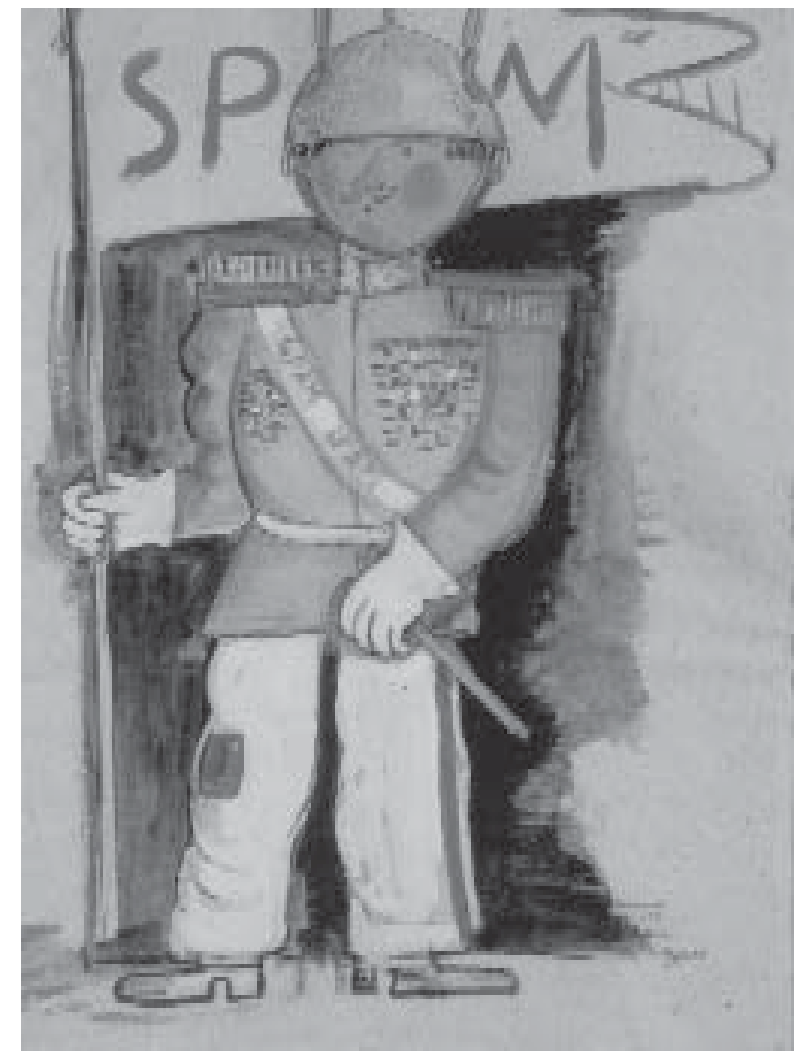

Lasar Segall, 0 porta-bandeira. Carnaval da SPAM, 1933 [Projeto para figurino]. Aquarela, guache e grafite. Museu Lasar Segall (fotógrafo Luiz Hossaka). 


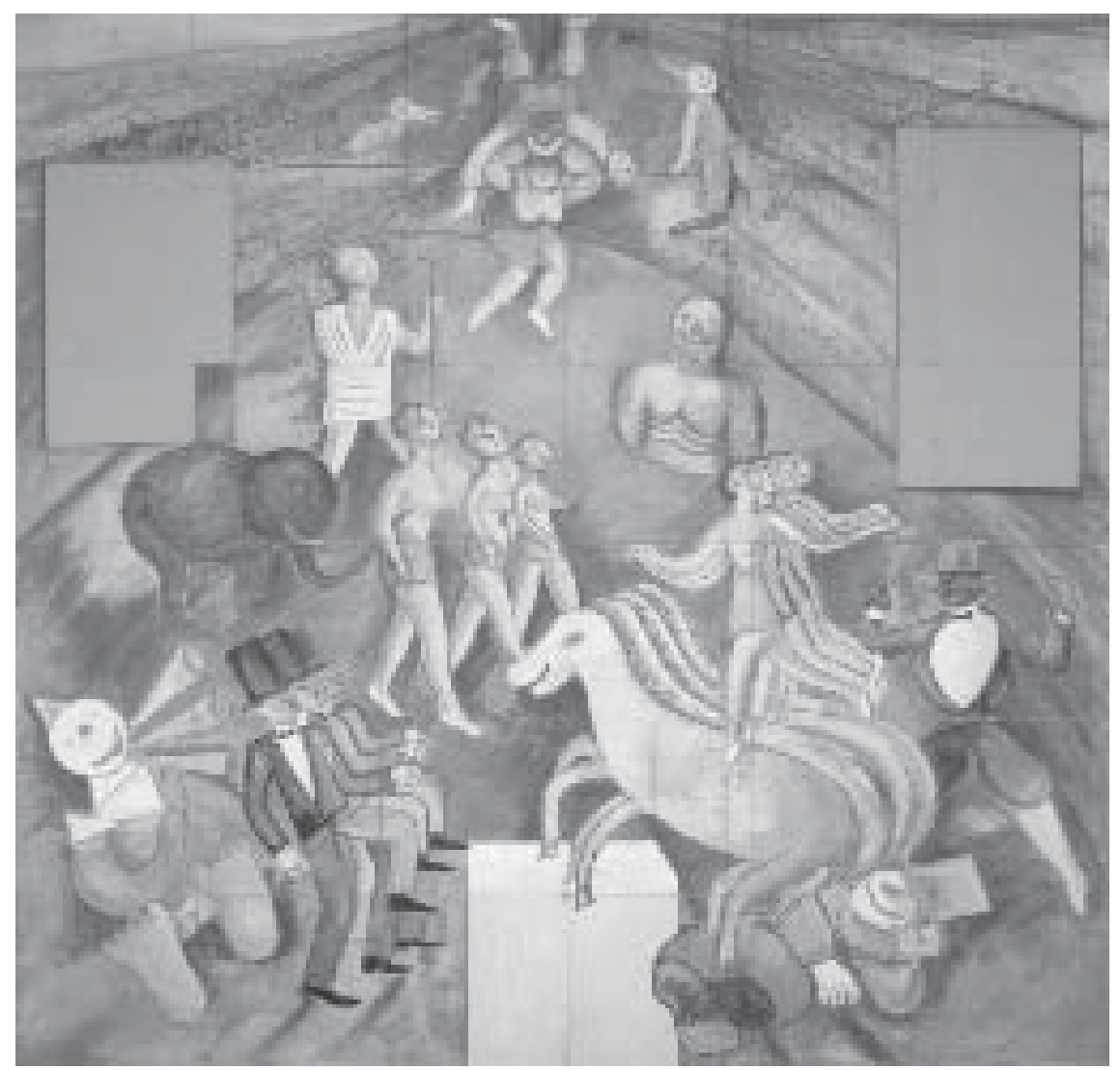

Lasar Segall, O circo. Carnaval da SPAM, 1933. Pintura guache. Museu Lasar Segall (foto L. Hossaka).

$N$ esses termos, a iconografia da cidade spamista revela ambigüidades presentes no posicionamento social do grupo responsável por ela. De imediato, é possível ler aí elementos de crítica à ordem social: a graça com que os marginais são retratados os aproxima das autoridades que sofrem um rebaixamento visual; a convocação para a festa sugere, a partir mesmo da onipresença das mani festações artísticas como marcadores da sociabilidade, certa anarquia que tende a invalidar a hierarquia tradicional, reforçada pelo clima onírico que deriva do conjunto das representações mobilizadas. Contudo, o viés crítico jamais avança sinalizando na direção de um horizonte de rompimento ou sequer de uma transgressão real dos padrões estabelecidos de vida social. Para aquilatar convenientemente tal interpretação, cumpre isolar as determinações próprias de qualquer festa daquelas específicas de um baile de carnaval e, finalmente, de um baile de carnaval da SPAM .

Em toda reunião social que se configure como celebração festiva, há de imediato uma supressão das diferenças sociais inscrita no ato do con- 
vite. Todos os convivas partilham uma mesma posição, que seu desempenho pode referendar ou não, o que está longe de significar um apagamento puro e simples da estratificação social; implica antes uma retradução da diferenciação para o grau de segurança no domínio dos códigos de distinção social, com grande destaque para o papel desempenhado pela moda. A legitimação tende a depender da positividade no uso da vestimenta, que redistribui no plano simbólico as marcações de posicionamento inicialmente negadas na unidade universal ista do convite. $\mathrm{N}$ uma festa à fantasia, no entanto, tal fenômeno está obliterado; a princípio, o traje leva muito mais ao embaralhamento dos sinais legíveis, segundo a grade de valores em questão, que à distinção. Tratando-se de um baile de carnaval, esse efeito é potencializado pela tradição de inversão simbólica dos papéis e de mistura entre os níveis alto e baixo de registro da posição e das expressões culturais correspondentes. $\mathrm{O}$ u seja, vestir-se de down, pirata, pierrô, mendigo, rei da França ou qualquer fantasia previamente registrada como cabível conta com idêntico grau de legitimação. As estratégias de distinção, quando desejáveis e morfologicamente possíveis, precisam recuar então para outras dimensões.

A SPAM encontrou seu modo de fazê-lo por meio da marcação quase obsessiva do pertencimento ao grupo que, como vimos, não dispensa 0 recurso da nomeação direta, além da ritualização estrita da encenação de caráter al go sinfônico que antecede a festa propriamente dita, imprimindo-Ihe o caráter desejado. $M$ as, de outro ponto de vista, é importante notar que, se a diferença entre spamistas e anônimos aponta para as fronteiras simbólicas entre São Paulo e a cidade de SPAM que guarda certo potencial crítico, a sofisticação da fatura segaliana no projeto das festas alerta para 0 aspecto puramente visual das demarcações construídas. É no afastamento visual entre as duas cidades que está o escopo da crítica social lograda pelo spamismo.Tudo se passa como se São Paulo fosse uma referência distópica irreal, plasticamente corrigida pela realidade imediata da cidade de SPAM . M as note-se que a crítica está circunscrita às questões urbanas, evitando nesse momento alusões ao nacional. E, mais importante, a coesão ideológica do projeto, manifesta na saturação expressiva alcançada pela integração dos signos, obtém a edificação de um universo visual coerente, eivado de deformação expressionista já assentada como arte modernista. Finalmente, o oferecimento desse universo ao compartiIhamento, cujas regras estão especificadas, com a cidade real, dá a ela um novo modo de visibilidade para si própria. 0 carnaval expressionista da 
SPAM , mais do que erguer uma cidade fantástica que exerça sobre São Paulo uma constrição normativa como uma utopia, viabiliza-se como nova visualidade urbana a partir da qual a cidade pode se contemplar. A crítica realiza-se assim como afirmação do modernismo expressionista que vislumbra tomar as ruas de São Paulo como já fez em relação à urbanidade da cidade cenográfica.

$\mathrm{N}$ a impossibilidade de contar com uma historiografia mais completa do desenrolar da festa, algumas informações esparsas ganham relevo. $0 \mathrm{~s}$ registros da SPAM destacam o sucesso do evento, assinalando que a decoração obteve "[...] surpreendente efeito artístico, sem dúvida um dos motivos preponderantes do extraordinário êxito. $\mathrm{N}$ ão foi, pois, apenas um baile carnavalesco, sendo principalmente uma fina nota de arte".

D e fato, sob vários aspectos justifica- se o êxito alegado. 0 cuidado com o preparo e a divulgação não só lotou os salões como garantiu repercussão na imprensa. 0 retorno financeiro também foi positivo, permitindo ainstalação da sede social, com a conseqüente ampliação do quadro social, 0 que dá maior segurança quanto à renda disponível. A SPAM torna-se mais conhecida pelo público em geral, adquirindo uma visibilidade que no plano político acirra astensões entre a Spamolândia e a sociedade nacional que a envolve; e que, transferidas para o interior do grupo, o levarão à extinção, conforme veremos. À festa não faltou inclusive um incidente ligado ao clima político da época: uma tropa do Exército que policiava as imediações do Trocadero, salão em que a festa ocorreu, intervém contra cantos de crítica ao regime recém-instalado entoados por convidados que saíam do baile.

Veremos na próxima seção que a segunda festa de carnaval mantém a estrutura do simbolismo da anterior, mas seu conteúdo recoloca em novos termos o problema da questão nacional.

\section{Asselvas da Spamolândia}

0 entusiasmo do grupo de Segall com os resultados obtidos leva a consolidar a festa como ponto alto da sociabilidade spamista, especialmente pela oportunidade de intervenção artística que a ocasião oferece. A pós o baile de 1933, duas outras festas serão realizadas com 0 mesmo caráter oficial e de abertura para a população em geral, mediante a venda de ingressos, ambas aproveitando a experiência anterior em seu contorno geral para acionar novos conteúdos representativos. A primeira delas acon- 
tece ainda em 1933 no H otel Esplanada, com o título propositadamente hermético de "Baile KWY", concebido pelo poeta modernista Guilherme de A Imeida. A única fonte capaz de render indícios para a análise é 0 convite, razão pela qual o registro aqui será limitado mas não irrelevante.

Toda a festa organiza se a partir do mistério em torno de seu nome, sendo seu ponto alto a entrega de um quadro do pintor Arnaldo Barbosa, do núcleo spamista, para aquele que der a melhor definição para a expressão. É ela o elemento principal de coesão simbólica, explorado já na face do convite, em que as palavras têm a seguinte organização gráfica:
Baile
K 0
$\mathrm{W}+$
Y spam...toso
Baile
KWY (que vi)

A brincadeira verbal sugere que a nova empresa do modernismo expressionista pende agora para o primeiro termo da expressão. Isso talvez explique em parte a falta de material visual sobre a festa e, aliado à ausência de Segall como mentor, sugira um grau menor de sofisticação plástica em relação à anterior. $M$ as conserva- se 0 hábito da nomeação exaustiva dos protagonistas: 26 deles estão listados no convite como membros da "C omissão Social". E a idéia de enigma guarda relação com o uso de um código dominado inteiramente apenas pelos insiders, além de reativar a estratégia da surpresa e do estranhamento. Se o tônus da festa modernista é devedor da habilidade com as palavras, no próximo episódio a profusão imagética segaliana retorna em sua plenitude.

Para o carnaval de 1934, a festa é concebida como uma viagem à selva inexplorada da Spamolândia, mote que dará unidade aos detalhes da decoração do rinque de patinação localizado na rua $M$ artinico Prado, que a abriga, e de modo geral a toda artesania plástica das representações envolvidas. Já no convite, em nome da fictícia agência de turismo da SPAM , responsável por "viagens fantásticas, aventuras alucinantes, sensações inéditas, perigos apavorantes, revelações estranhas" que "transformarão 0 mundo da ciência", informa-se ao público que sua participação na" G rande Expedição às M atasVirgens de Spamolândia", nome oficial do evento, 0 porá em contato com "o ritmo misterioso e fascinante da floresta spamo- 


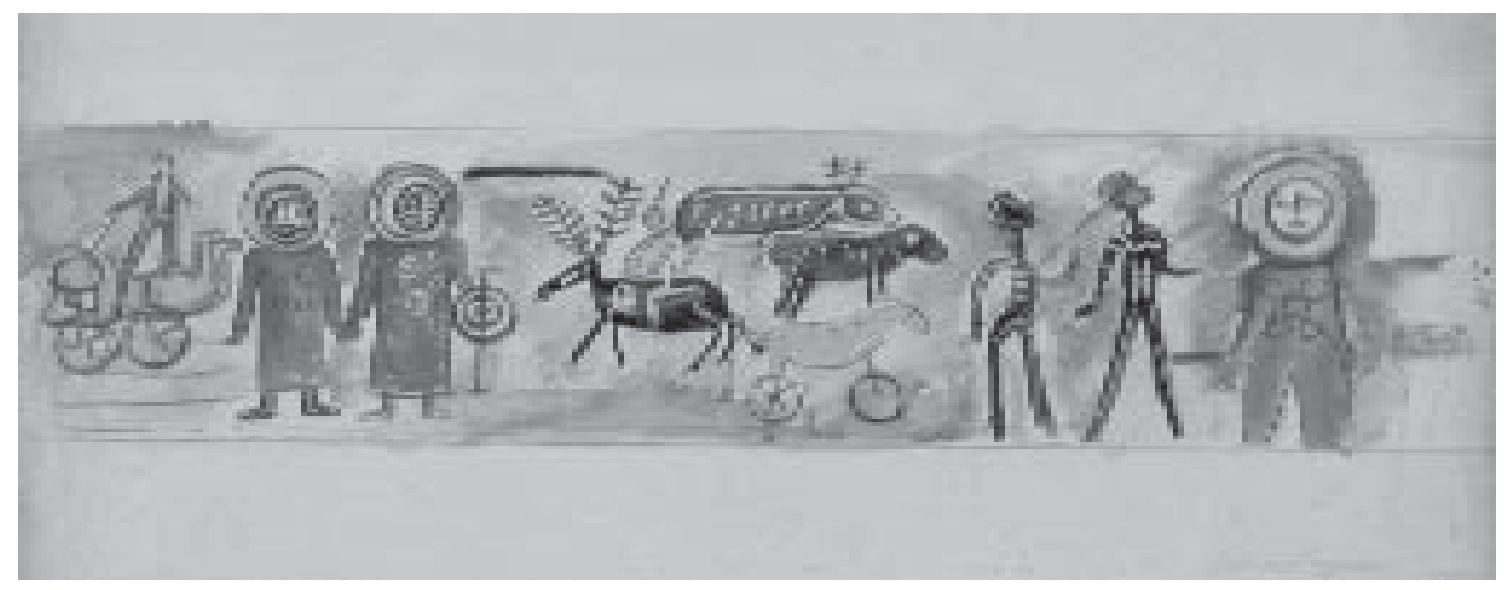

Lasar Segall, Projeto para decoração. Carnaval da SPAM, 1934. Aquarela e guache. Museu Lasar Segall (fotógrafo Luiz Hossaka).

landeza; a flora deslumbrante, a fauna assombrosa de Spamolândia; o 'it' romântico dos rudes indígenas spamolandezes".

Para garantir a adesão a esse universo desconhecido, os organizadores esmeram-se na construção de um imaginário a ser compartilhado com os convivas, descrevendo- o meticulosamente no convite, sob a rubrica "informações gerais":

Spamolândiaé uma região inexplorada que, apesar de seu interesse geográfico, geológico, climático, histórico, etnológico e cultural, não figura nos mapas oficiais.

C aracterizam- na a fantasmago ria festiva da vegetação fecundíssima, os fenômenosatmosféricos de feérico efeito e o caleidoscópio bizarro da zoologia fabulosa. $\mathrm{N}$ as suas florestas virgens pululam fantásticos e robustos espécimes de monstros antidiluvianos.

A exata situação geográfica de Spamolândia é a seguinte: entre o Pólo N orte e o Pólo Sul, a 180 de longitude. Este e 0 este de seu antimeridiano.

A descoberta de Spamolândia data do período compreendido entre os anos 1 e 1934 da nossa era. A glória imortal dessa descoberta coube ao heróico navegador solitário Spaminondas, o qual, num nobre gesto spamtriótico, içou o pavilhão de Spam no novo território.

O sindígenas spamolandezes sempre cultivaram as artes, dedicando-se principalmente à música e à dança. Atingiram um alto grau de maestria na mais perfeita expressão musical da história spamolandeza, um conjunto estranho e barulhento de instrumentos bárbaros, denominado jazz. São igualmente peritos no domínio das danças exóticas denominadas rumba, ranchera, tango, val sa, marcha, maxixe, foquestrote etc. 
N umerosos vestígios disseminados por toda Spamolândia parecem confirmar uma interessante teoria dos cientistas mais acreditados. $\mathrm{N}$ a opinião desses círculos eruditos, os spamolandezes teriam criado em tempos pré- históricos obras de pintura e escultura que, pela perfeição plástica, ultrapassariam tudo que se tem realizado desde então no domínio das Belas-A rtes. Prevê-se que as pesquisas em torno dessas obras-primas virão revolucionar por completo os destinos da arte universal.

A exemplo da festa anterior, há também um episódio central da encenação:

O Príncipe Carnaval, elegante e popular herdeiro da coroa de Sua M ajestade Momo, fará parte da expedição a convite especial da Spam, realizando-se no monte Spamor um encontro histórico entre SuaAlteza e o famigerado rei dos canibais Spaman-U Ulah. Tomará parte no soleníssimo cerimonial a fina flor da sociedade antropófaga.

Avante spamaradas!

À conquista dos mistérios de Spamolândia!

0 período citado descreve a cosmologia criada para dar sentido ao baile, que coube a Segall materializar. C onserva- se assim a estrutura, calcada na montagem de um simulacro fantástico do real e no andamento cênico que inclui um episódio de celebração que segue um rígido protocolo, o que permite manter a interpretação anterior, atentando para as novas nuanças. Assim, quanto ao primeiro ponto, a riqueza da fabulação é comparativamente maior na medida em que implica expandir o horizonte spamista para além da cidade, com a convocação de elementos que evocam a natureza e o primitivo, ao passo que se atenua a marcação do pertencimento à SPAM como signo de distinção. $N$ ote- se que na lógica da fabulação o público da festa tem o mesmo papel simbólico de expedicionário que os spamistas, exceção feita aos que representam os papéis indispensáveis à encenação (por exemplo, o Príncipe $C$ arnaval encarnado pelo ator Procópio Ferreira); todos juntos, subsumidos pela categoria de "spamaradas", descobrirão a reunião do tropical com o pré-histórico que caracteriza a topografia do lugar e sobretudo a produção artística dos autóctones.

C resce então a importância dada às artes plásticas, cujas realizações nativas estão no plano do inalcançável, conforme atesta a opinião científica. $\mathrm{O}$ u seja, Segall coloca-se no lugar simbólico do primitivo habitante 
da Spamolândia, autor de um tipo de arte a ser descoberta, sutil deslocamento em relação à elite que o cerca: a distância que interessa marcar aqui não é mais entre o grupo e seu exterior, mas recua para dentro. De imediato, essa postura reflete as tensões vividas na entidade, do desagrado da parcela artisticamente mais inquieta com a postura esnobe que ampara à divisão entre judeus e não-judeus. Esta última, secundada pelo entusiasmo de al guns com o integralismo (O lívia G uedes Penteado, M enotti del Picchia), porá fim à SPAM . Para além disso, revela também a reserva de Segall em relação ao clima nacionalista, que breve passará a convocar a capacidade de desvelar o país nos conteúdos imagéticos criados como critério de juízo estético. A "brasilidade" não faz parte da arte desses gênios intemporais, que, no entanto, são canibais como os tupinambás e antropófagos como os modernistas, e vivem na selva.

A criação das matas virgens da Spamolândia envolve portanto o paradoxo de pontuar o distanciamento em relação ao nacional no mesmo movimento em que inadvertidamente convoca a questão e se nutre de alguns de seus símbolos. Antes de analisar a cenografia da festa, em que Segall trabalha plasticamente o problema referido, cumpre continuar o paralelo enfocando o segundo aspecto estrutural mencionado, que inclusive segue tangendo o mesmo paradoxo. 0 encontro entre o Príncipe $C$ arnaval e 0 rei dos canibais é descrito do seguinte modo:

Personagens: o rei Spaman-U Ilah, sua veneranda dupla de esposas (extremamente feias e velhas), o feiticeiro - ministro - curandeiro - mestre de cerimônias (de aspecto pouco recomendável, mas de talentos variados e grande alcance político), meia dúzia de guerreiros decrépitos, uma dúzia de ferozes guerreiros na flor da mocidade, força e beleza máscula conforme a tradicional estética canibalesca, oito donzelas radiantes de graça e virgindade, meia dúzia de talentosos tocadores de barris de cerveja disfarçados em tambores, duas graciosas moças armadas de espanadores, cujo mister será abanar com dedicação a majestosa carcaça do rei da tribo, o Príncipe C arnaval, que viajando inoficialmente será acompanhado apenas por um pagem e o bobo da corte.

C erimonial num palco especialmente armado na festa.

Primeiro coloca-se o grupo de tocadores de tambor. D epois o rei dos canibais com cerimônia e acompanhamento vocal e instrumental, ministro - feiticeiro e o resto da tribo executando passos de dança.

A núncio da chegada do Príncipe $C$ arnaval maisbanquete em sua honra: donzelas carregam para o palco marmita colossal para o preparo do misterioso prato do 
dia. Q uatro guerreiros precipitam-se sobre o Príncipe e o jogam no fundo da marmita sob seus protestos. Cobrem a marmita, a tribo dança em torno dela, que é descoberta, retirando-se os restos assados do que há pouco fora um príncipe.

Sendo essa a informação disponível sobre 0 andamento planejado da festa, depreende-se que o protocolo se mantém, bem como a distribuição das personagens segundo sua função cênica, mas a construção sinfônica cede espaço para um único episódio de grande força expressiva. 0 Príncipe C arnaval, possível habitante da cidade de SPAM , é canibalizado ritualmente pelosselvagens daSpamolândia, signo provável do canibalismo cultural que passa a integrar o conjunto de recursos de que Segall dispõe a partir de seu contato com o grupo modernista. A qui o carnaval serve de moldura à cristalização de representações que se abrem a uma plêiade de interpretações possíveis, não isentas inclusive de conotações sexuais. N os limites deste estudo, interessa sobretudo seu caráter surpreendente, um toque de grand guignol em nome da alegria que silencia assim seu enraizamento no repertório daquelesque o organizam.Vale notar também que os canibais da Spamolândia usam em seu rito uma marmita, emblema do modo de vida proletário, o que contribui para o embaralhamento dasreferências: 0 aceno em direção ao popular, ai nda que velado, corre em paralelo com o apelo estético ao primitivo, ambos marcadospelo signo da estrita necessi dade de alimento e de expressão artística.

M esmo não sendo possível atestar, por falta de dados, que os fatos transcorreram conforme previsto, o que está projetado lança luz sobre a ambigüidade do posicionamento de Segall, seja no país, no interior da elite que 0 abriga, no círculo modernista ou mesmo no grupo mais restrito cuja identidade se vai moldando por meio daSPAM . A maneira mais concreta de acompanhar a resolução dos problemas montados, no entanto, é voltando a atenção para a cenografia, em que a habilidade de Segall consiste em frustrar a expectativa criada sem prejuízo da qualidade estética. 0 esmero da realização já é em si signo legitimador do posicionamento simbólico sugerido; e, de fato, o baile de 1934 conta com um grau de invenção estética mais sagudo que 0 anterior. Fundamental mente, o recurso usado para obter 0 efeito desejado combina a mistura de referências visuais com 0 amplo apelo à arte africana - desde sempre uma importante fonte da produção segaliana. 0 grande espaço disponível no salão é um desafio a mais, mas a equipe de colaboradores permanece composta por spamistas já experimentados. 
Todo o espaço deve simular uma grande floresta, repetindo o uso de painéis pintados e, como grande inovação cenográfica, recorrendo agora a objetos tridimensionais. U ma espécie de tenda pende do teto do salão, rebaixando o excesso de altura e, por meio de enormes faixas de tecido que fazem as vezes de fol has, provendo a atmosfera de toques florestais. As figuras que povoam os painéis, circundadas por temas vegetais, dividemse basicamente em animais e índios. A fauna spamolandeza inclui elefantes, veados, macacos, morcegos, inúmeros tipos de pássaros, insetos. Vários entre esses espécimes têm características muito peculiares: alguns se aproximam em suas formas de monstros pré-históricos, os chifres de um antílope lembram um caramujo, há um veado de duas cabeças, uma borboleta antropomórfica de proporções gigantes faz par com um morcego também dotado de face humana. Essas figuras povoam paredes e portas, por vezes pendem do teto, e algumas são armadas tridimensionalmente; na coluna central está enrolada uma enorme cobra. Q uanto à representação dos aborígines, tem-se invariavelmente figuras de negros, de formas arredondadas, quase sempre empunhando algum tipo de instrumento - seja musical (tambores), ritual ou armas de guerra. 0 s indígenas de Segall são inequivocamente inspirados em tribos da África, assim como a fatura artística em geral da decoração é devedora de sua familiaridade com a "arte primitiva" responsável pelas máscaras africanas tão afins da deformação expressionista.

Em seu conjunto, a decoração, com sua profusão de cores - em que predominam mais uma vez os tons de ocre, terra, amarelo e laranja - e formas inusitadas, que se espalham inclusive pelo espaço aéreo, obtém 0 esperado clima de mistério e surpresa prometido aos expedicionários, ao passo que materializa plasticamente as colocações e os deslocamentos já comentados de Segall. N os relatórios da SPAM, há o seguinte registro sobre a festa:

A pista de patinação da rua M artinico Prado foi transformada numa bárbara selva, onde os animais de fauna pré- histórica pululavam ao lado de outros cujo aparecimento a cronologia ainda não relatou. Foi sem dúvida uma obra gigantesca no gênero, em que predominou o senso artístico, e que provocou grande curiosidade não só na imprensa e nas classes mais elevadas, como também no público em geral - o que não foi difícil constatar, dada a insistência das visitas com que unse outros nos honraram - , sendo to dos concordes no afirmar tratar-se de uma realização excepcional, em que a nota de um justo equilíbrio artístico predominava. 


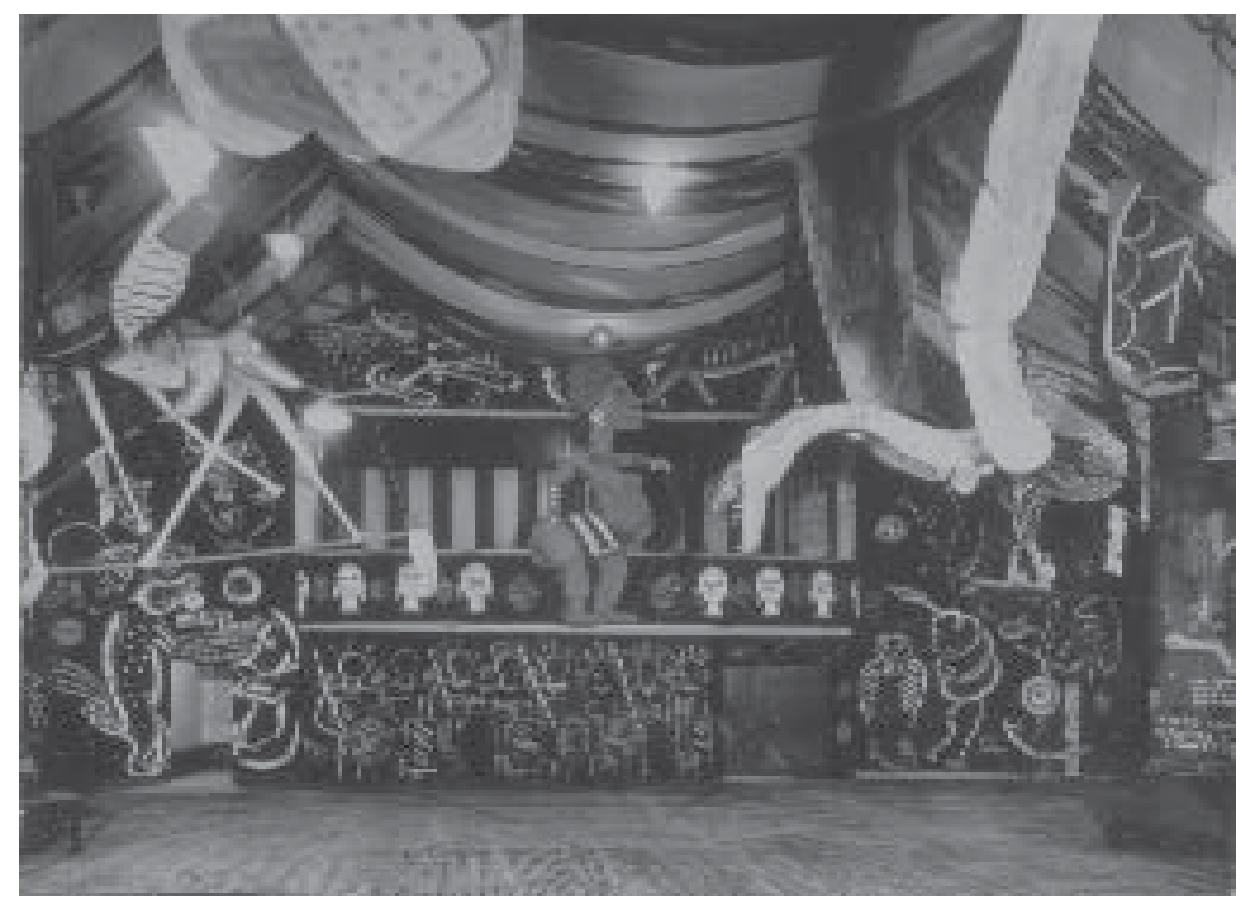

Lasar Segall, Expedição às matas virgens de Spamolândia [Decoração do baile de carnaval da SPAM], 1934. Museu Lasar Segall (fotógrafo Luiz Hossaka).

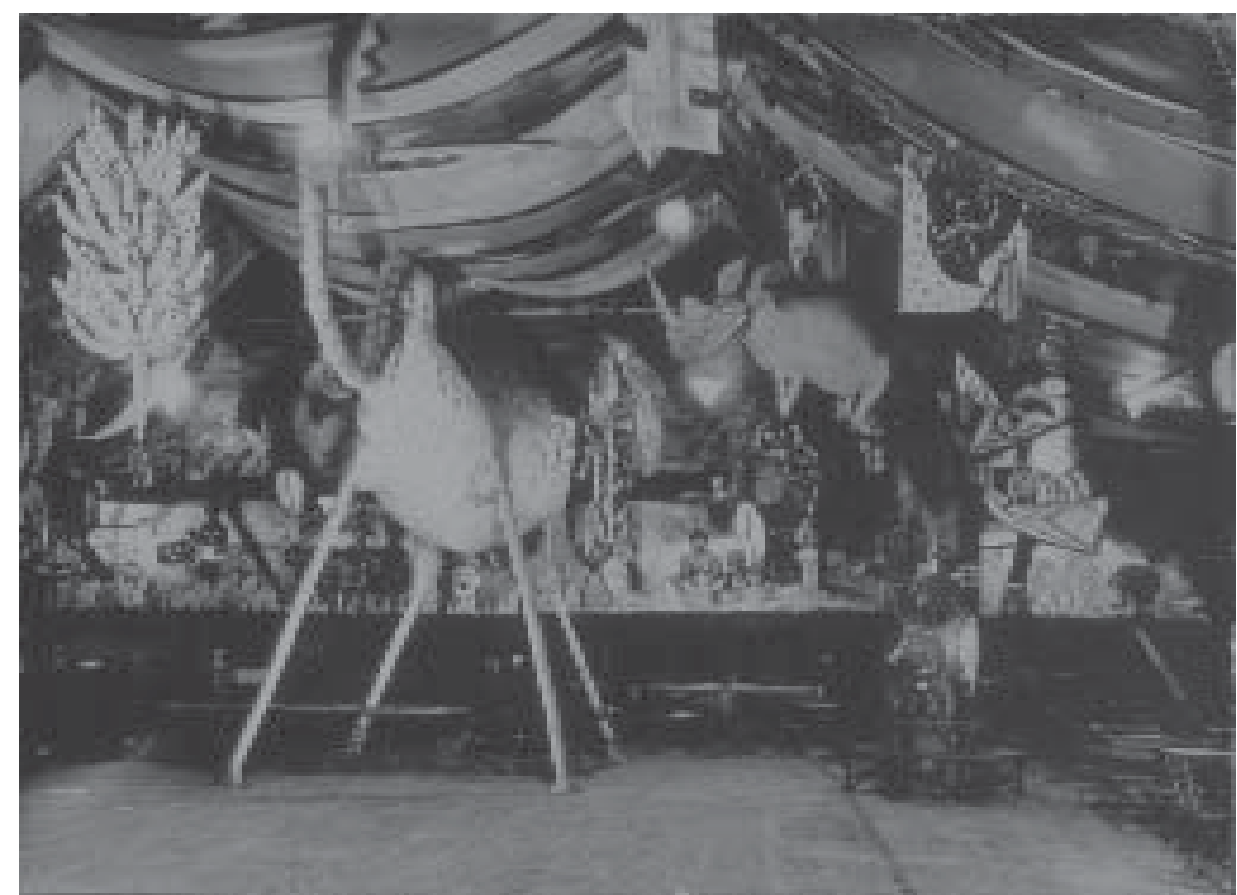

Lasar Segall, Expedição às matas virgens de Spamolândia [Decoração do baile de carnaval da SPAM], 1934. Museu Lasar Segall (fotógrafo Luiz Hossaka). 
Seu projeto, bem como sua direção geral, foram de autoria de Lasar Segall, cujos esforços constituíram, sem favor, o eixo central do extraordinário sucesso alcançado e que a imprensa registrou.

No entanto, a essa altura as divergências no interior do grupo já tomam uma proporção tal que inviabilizam composições. Em carta de 23 de abril de 1934, Paulo M endes de AImeida externa seu desconforto a Segall:

\section{Lasar, amigo - \\ Saudades.}

Eu não desejo assinar o relatório da Spam com o meu nome individual. 0 motivo é muito simples: com meu nome eu não seria capaz de elogiar muitos dos empreendimentos da Spam. C omo você sabe, desde a primeira reunião, em casa de d. $M$ ina, a sociedade tomou rumo diverso do que eu sonhara. Como membro da comissão, curvei-me sempre, com grande liberalidade, às imposições da maioria. $\mathrm{N}$ ão me arrependo disso. Antes, pelo contrário, constitui, para mim, padrão de orgulho esse espírito democrático, igualitário, de que felizmente se impregnou 0 meu caráter*. 0 fato, porém, é que, seja porque não o tivesse querido ou seja porque não o tivesse podido, nem sempre a orientação da Spam tomou o rumo da minha vontade. N ão éjusto que agora se me imponha a obrigação de publicamente vir elogiar essa obra, em meu nome individual - quando tantas restrições teria a fazer. Por exemplo, eu sou incapaz de dizer, no meu nome pessoal, "nossa melhor sociedade" etc., coisas que tantas vezes ali são repetidas, pois não acredito que haja sociedade melhor, mesmo porque, em geral, a "melhor" é a pior [...].

R ecado apressado do amigo certo

Paulo

*É um dos traços comuns que formam a essência idêntica do espírito judeu!

0 texto de Almeida é emblemático do tipo de conflito que levou à dissolução da entidade, ao mencionar seu caráter bifronte aludindo ao "espírito judeu". R evela a dissintonia entre judeus e magnatas, conforme os grupos em disputa passam a se chamar, e a consciência, mais importante no âmbito deste trabalho, a respeito do jogo social em que a arte era 0 meio simbólico, moeda de troca de afinações e distanciamentos no horizonte da estratificação. $\mathrm{N}$ a configuração que o conflito adquire, os “ju- 
deus" congregam todos aqueles que se sentem desconfortáveis em relação ao arranjo entre produtores e consumidores de arte, entre artistas e seus mecenas, que deu origem à SPAM, porque as disparidades se tornaram demasiado explícitas. Por outro lado, a designação reverbera 0 antisemitismo latente no corpo social, que leva alguns setores a se manifestar na imprensa contra a estética de artistas "neo-brasileiros", em alusão aos judeus. É particularmente contundente um artigo de José Bonifácio de Souza A maral no D iário Popular de 21 de fevereiro de 1934, intitulado "O s fins secretos da Spamolândia", em que o autor, após indignada peroração, procura mostrar o perigo que a sociedade representa para as tradições brasileiras e a moral cristã. 0 impacto do escândalo na SPAM é desestabilizador, já que força os limites de exposição da parcela de "nossa melhor sociedade" ali encastelada. Em 25 de novembro de 1933, Segall demite-se da C omissão Executiva. N o ano seguinte morre 0 lívia Guedes Penteado. Subitamente privada das figuras capazes de fazer as mediações dos conflitos latentes, a sociedade não tem mais como se sustentar.

N oscerca de dois anos de duração da SPAM , suas realizações têm grande importância na perspectiva interna ao projeto de Segall, aspecto que se ilumina a partir de outro braço de sua ação estética.

Durante o período de vigência da SPAM, Segall funda a Escola de A rte Lasar Segall, dedicada ao desenho, à pintura, à composição e à gravura em variadas técnicas, que funcionou por curto período. 0 panfleto de divulgação dos cursos dá acesso a al gumas de suas idéias so bre a arte e seu ensino:

A idéia fundamental que deve inspirar o ensino numa escola de arte é a seguinte: Cada qual tem que dominar o superficial na natureza e na arte em favor do essencial.

Superficial é a aparência, o fugitivo, o requintado, tudo que é "bonito" no sentido comum da palavra.

A sua antítese é o Verdadeiro, o necessário, o constante, o que se revela e aparece lentamente.

É importante que sejam ensinados os recursos técnicos da cor e da linha. Seria porém reprovável estabelecer princípios comuns e regras gerais para o trabalho. Isso conduziria à eliminação do elemento pessoal.

C ada qual deve ser apenas estimulado a apreender por si mesmo 0 essencial na natureza e na arte, e a exprimi-lo em sua maneira individual e necessária- isto é, deverá encontrar o seu caminho próprio. 
Para além da reiteração dos alicerces da estética segaliana, centrada no verdadeiro/ necessário/ essencial, o documento, de final de 1933, revela a preocupação de seu autor com a independência do artista jáno momento de sua formação, alertando para o perigo da adesão sem mais aos padrões vigentes. M as, ao comentar o que deve ser evitado, à categoria estética do belo associa-se a categoria social do requintado. 0 u seja, o requinte que uma fração da elite procura obter justamente associando-se à estética de Segall é detectado por ele e com toda clareza pejorativamente assinal ado no âmbito de uma instituição de ensino - que, de resto, controla com absoluta independência. Segall demonstra consciência a respeito da modalidade de sua integração, que transparece em produções como as cenografias das festas, cuja qualidade plástica é preservada das injunções sociais tratadas anteriormente.

A lém disso, é sintomático que a escola seja contemporânea da SPAM , mas a preocupação didática que as aproxima tem inflexões diversas, conquanto partilhem o objetivo de legitimar certa concepção estética. N 0 primeiro caso, trata-se de ensinar artes plásticas para vocacionados; no segundo, como vimos, o escopo amplia-se para a oferta de um padrão de visual idade dirigido à cidade e ao conjunto da sociedade, que para se viabilizar recorre a uma parte da elite que o assume como estratégia de distinção. Enquanto pôde manter esse equilíbrio delicado entre demandas sociaise produção artística, Segall teve naSPAM a oportunidade de, rompendo a cisão entre arte e artesanato e infundindo arte nas várias esferas da vida, aproximar-se da utopia da obra de arte total, assimilada por ele ainda na A lemanha a partir de seu contato com a Bauhaus.V istas em conjunto, as festas apontam claramente nessa direção, mas as vicissitudes da realização da hora plástica de Segall - para usar uma expressão do crítico M ário Pedrosa - podem iluminar-se quando localizadas na teia de relações sociais em que são vividas e que contribuem para fazer existir, como tentei demonstrar ao longo da argumentação.

\section{Referências Bibliográficas}

AyALA, Walmir. (1986), D icionário de pintores brasileiros. R io de Janeiro, Spala.

BAST IDE, R oger. (1997), A rt et societé. M ontreal, L'H armattan.

BAT ISTA, M arta; Lo PEZ,TelêA ncona \& LIM A,Yone. (1972), B rasil: primeiro tempo modernista. São Paulo, IEB/ U SP.

Beccar I,Vera. (1984), L asar Segall e o modernismo paulista. São Paulo, Brasiliense. 
Bour dieu, Pierre. (1996), A s regras da arte. São Paulo, C ia. das Letras.

C Am Ar Gos, M árcia. (2001), V illa K yriall: cônica da belle époque paulistana. São Paulo, Senac.

C An Did o, Antonio. (1976), L iteratura e sociedade. São Paulo, Cia. Editora N acional.

DuArte, Paulo. (1985), M ário de A ndrade por ele mesmo. São Paulo, H ucitec.

Dur an d, J. C arlos. (1989), A rte, privilégio e distinção. São Paulo, Perspectiva.

ElIAS, N orbert. (1995), M ozart, sociologia de um gênio. R io de Janeiro, Z ahar.

Fabr IS, Annateresa. (1994), 0 futurismo paulista. São Paulo, Perspectiva.

H ASKel, Francis. (1997), M ecenas e pintores. São Paulo, Edusp.

LAfetÁ, João. (2000), 1930: a đítica e o modernismo. São Paulo, Editora 34.

LePenies, Wolf. (1996), A s três culturas São Paulo, Edusp.

M Aтto S, CláudiaValadão. (1997), L asar Segall. São Paulo, Edusp. . (2000), L asar Segall: expressionismo e judaísmo. São Paulo, Perspectiva.

Mello e SouzA, Gilda. (1996), 0 espírito das roupas. São Paulo, Cia. das Letras.

M ICELI, Sergio. (1996), Imagens negociadas. São Paulo, Cia. das Letras.

M ILLER , Alvaro et al. (1982), L asar Segall: antologia de textos nacionais sobre a obra e 0 artista. R io de Janeiro, Funarte.

N aVes, R odrigo. (1997), A forma difíal. São Paulo, Ática.

Segall, Lasar. (1993), Textoș depoimentos e ex posições. São Paulo, Biblioteca Jenny K la bin Segall.

Z AN IN I, Walter. (1991), A arte no B rasil nas décadas de 1930-40. São Paulo, Edusp.

\section{Resumo}

A partir da análise da produção visual de L asar Segall no âmbito das festas da SPAM , o trabalho busca iluminar as ambigüidades de seu posicionamento no interior da elite que 0 abriga. $\mathrm{N}$ esse movimento, trata-se de atentar para 0 uso da arte como mecanismo de distinção social e o manejo que Segall logrou realizar desse dispositivo. Palavras-chave: Arte; D ecoração; Elites; D istinção; M odernismo.

Fernando Antonio Pinheiro Filho é doutor em Sociologia pela U SP, professor de Sociologia na USP e na FESPSP. 